\title{
Longing for equal status: impact of housing intervention on identity and status of Indian origin Tamil resettlers from two selected plantations in Sri Lanka
}

\author{
Anton Piyarathne
}

Department of Social Studies, Faculty of Humanities and Social Sciences, The Open University of Sri Lanka, Nawala, Nugegoda

\begin{abstract}
Often the relationship between majority groups and the minority groups are beset with problems. In most societies, minority groups experience exclusion, lack of recognition and under privileges. They face difficulties in interacting with mainstream society dominated by privileged groups. Tamils of Indian origin who came to Sri Lanka to work in coffee, tea and rubber plantations during the British period, are considered one of the minority groups in Sri Lanka. They have been marginalized by mainstream society in a number of ways, resulting in their continued low social status in society. Some of the developmental interventions of the government were successful in altering the unfavourable status of the Estate Origin Tamils. A study was conducted to understand how far and in what ways the housing interventions in the plantation sector served to enhance the social status of Estate Origin Tamils. This paper provides a summary of the findings of this study.
\end{abstract}

\section{INTRODUCTION}

Social status is one of the key concepts in Sociology. Dignity is one aspect of a person's social status. This paper discusses the concept of social status with reference to the Tamils of Indian origin who live in plantations in Sri Lanka. Plantations have a residential population of approximately 850,000 comprising over 240,000 resident families (Malwatte, 2000). The study has covered Nuwara Eliya and the Kalutara districts where there are two main cash crops, namely tea and rubber. The concept of status is referred to in Sinhala as thathwaya and thanak, and in Tamil madippu and samuha anthasthu. Through 150 years of life and labour on the plantations, the identity of the estate Tamil community has come to be defined by and large as "outsiders" (Philips, 2001). Estate space takes on symbolic gendered connotations as "mother" (fertile, nurturing, life-giving) and as "female". A middleaged man described, in rather poetic terms, "children without mothers", which was an obvious allusion to the predicament of the Indian Origin Tamils (IOT) as people without their own space (motherland, social space). He went on to explain that the thottam (estate) had become their mother. Estate space and work are inextricably linked in the estate residents' perception of their own identity, particular among the older generation of the workers (Philips, 2001). The social status of the Estate Origin Tamils was based on a living pattern that was centred around the estate "line rooms". They were unable to share a privileged status in the society comparable to that of "the dominant groups". The social identity they acquired was that of a low status and they have been discriminated by the ethnic majority Sinhalese people, as well as by the Jaffna Tamils in spite of sharing a common language. The British planters ensured that the Tamils who had migrated to the plantations did not mix with the local communities. They were geographically and socially isolated in the plantations. The Indian Tamils who had migrated emerged as a relatively closed community confined to the territorial boundaries of the plantation (Hollup, 1994). For the first time in Sri Lankan history two major life-worlds emerged; that is gama (village) and watta (estate). After the Indian Tamils were brought to the estates, they were accommodated in line rooms with limited space and minimum facilities. Each barrack building consisted of 10-12 line rooms. The double line, with back to back housing contains as many as 24 households (Hollup, 1994). There was no proper understanding or trust between the indigenous Sinhalese people and the immigrant Tamils. The Sinhalese villagers labelled them using derogatory terminology such as demalu (Tamils), wathu demalu (Plantation Tamils), 
watte aayo (estate Tamils), and layime aayo (Tamils in line housing). The Jaffna Tamils have labelled them as thottakkattan (plantation-jungle-man), malaiyakkathan, vadakkathiyan (upcountry people), and kallathony (illicit boat-person). The Indian Origin Tamils resented such terminology (Daniel, 1992). These Tamils highly emphasised the need for achieving a positive social status, improving their living conditions, and seeking an improved social status. They felt that they were not accorded a satisfactory social status and they were not respected like others in mainstream society. Some successfully moved out from the estates to the cities such as Colombo and Kandy, earned good money and their family members received a good education.

This paper examines how far and in what ways resettlement in new housing schemes changed the identity and social status of Tamil persons of plantation origin. As the estate workers were living in line rooms, they existed in isolation as an un-integrated segment of the country's population as mentioned at the beginning of the article. After independence, the Sri Lankan government initiated a number of development interventions in the plantation sector, including the provision of welfare facilities in education, health and housing. Following economic liberalization in 1977, interventions in the estates resulted in a change in the lifestyles and aspirations of families. Government-owned plantations were handed over to private companies for enhancing their profitability and sustainability. The younger generations in the estate entered a free labour market and are earning more than they did earlier, but they live in the same line rooms given to them by the colonial estate management. At the beginning of 1980, the government started the selfhelp housing schemes in villages as well as in estates under a number of housing development programmes. A small percentage of estate families benefited from this programme. Later the government decided to offer seven perches of land and financial facilities to help build houses for estate residents under the People's Alliance regime established in 1994. The People's Alliance government implemented "village type" settlement programmes in the plantation areas. According to my observations, the government interventions towards housing development on the estates paved the way for further changes within the plantation community.

Sri Lanka is a heterogeneous society consisting of Sinhalese, Tamils, Muslims, Burghers and diverse religious groups. Though they live harmoniously for the most part, from time-to-time misunderstandings and tension between these communities have erupted. A major civil war prevailed in the country from 1983 to 2009. The need for integration between Sinhalese and Tamil communities has often been emphasized by researchers, writers, and policy makers. War between the Liberation Tigers of Tamil Eelam (LTTE) and the Government forces did not involve the Tamils of plantation origin, but the latter too were victims of a number of ethnic riots from 1983 onwards. Terms such as plantation workforce, estate population, Indian Tamils and stateless persons have been used to identify workers in the plantations (Peiris, 1996). In official government records and even at the level of group consciousness, there is a distinction made between the Indian Tamils of plantation origin and the Sri Lankan Tamils who include the traditional Tamil inhabitants originating from Northern and Eastern parts of Sri Lanka (Sivathamby, 1995). The study focused on Indian Origin Tamils who are also called "Estate Tamils" and "Plantation Tamils" depending on the context. However, the paper uses only the term Indian Origin Tamils (IOT) to refer to the tea and rubber estate based Tamil community and the term Estate-Origin Tamils (EOT) to refer to the Tamils living in the line rooms. The need to integrate the plantation with the village was accepted, as it is in several ways necessary for the future wellbeing of the plantation worker communities as well as the village inhabitants (Moonesinghe, 1995). Social status plays a key role in the social interaction between estate residents and surrounding communities. It is also important from the angle of nation building (Moonasinghe, 1995).

\section{THE OBJECTIVES}

There are four objectives in this paper. First, it examines the effect of housing schemes on the lives of the estate origin Tamils (EOT). Second, the paper seeks to understand the influence of housing schemes on the social status of the EOTs. Third objective is to explore how far the dominant group (Sinhalese community) accept status change among EOTs. Fourth objective is to understand how housing interventions impact on the interaction among settlers, estate residents, and the Sinhalese people who live in the vicinity.

\section{LITERATURE REVIEW}

Bandarage (1950) provides a theoretically informed interpretation on the impact of the British plantation economy and political authority on the Kandyan highlands of the country during the nineteenth century. It also deals with the wider questions of development and underdevelopment in the third world taking Sri Lanka as 
a case study. She found that Non-goigama castes of the Sinhalese society such as Karawa, Durawa, Salagama entered various activities of the estate sector. They made profit and formed a new social class. Bandarage also indicates that due to the ethnically based division of labour, and lack of assimilation in plural societies, the ethnic groups interacted with each other only in the market and economic sphere as was also stated by Furnivall (1878-1960) and other theorists. Her political economic analysis of Kandyan highlands between 1833 and 1886 identified the root causes of the lower social status of the Tamil workers of Indian origin. The ethnicity based division of labour weakened the development of education, infrastructure and political processes in the estate sector, which jointly contributed towards maintaining the lower social status of the plantation workers in Sri Lanka.

Shanmugaratnam (1997) emphasises the need of incorporating the Tamil community into the broader system of national education, health, housing and the developmental programmes, and assurance of the right to own a plot of land, facilitating them to live as free citizens who can satisfy their needs. While mentioning the housing and land issue, he emphasises the need to liberate them from the institutions and culture of the estate line rooms which persists as a powerful symbol of their history of captivity and segregation. His ideas on the line rooms are very important because it discusses the negative status associated with life in line rooms and gives the clue as to how it can be changed. He further emphasises the need of addressing the social and psychological issues of the Tamils living in the estates towards developing a broader Sri Lankan consciousness. Though Manikam (1995) discusses the privatization of the tea plantations and related issues, he also mentions about the need of addressing the land and housing issues of estate residents. He states that the estate residents are "crowded into damp, smoky and dark hovels, severely affecting their health and creating enormous social and psychological stress". He stresses the need to provide decent housing for the estate residents. The Presidential Secretariat (1996) refers to the need to develop new housing settlements and giving the land ownership to estate residents. The report suggests that these measures would enhance the social identity of estate residents.

Jayaweera (1991) mainly considers the situation of women of the plantations. According to Jayaweera there is upward mobility in occupations, education and the economical status, but the dwelling does not support one in getting the due social prestige or respect since the majority of Tamils live in line rooms. Jayaweera and
Shanmugam (1993) discuss the changing aspirations of the plantation families with a focus on their desire for status mobility. "The rising levels of aspirations for their children indicate that the horizons of at least some of these families were expanding beyond the plantation borders". They highlight the need of studying the housing interventions in the plantations that they could not cover in their study. Uyangoda (1995) studied rubber tapping women in the Glandon Estate in Kalutara district. He notes how the lack of decent housing conditions in the four estates of the Kalutara districts had a negative impact on their social status.

Hollup (1994) examines the factors that made it difficult for Tamils of Indian origin to escape wage labour on tea and rubber plantations. Hollup emphasises the lack of opportunities for advancement through educational and occupational pathways outside the plantation sector. $\mathrm{He}$ discusses some social status issues and the convergence of ethnic and class-consciousness within the community. However, he did not examine social status of TIO in the wider Sri Lankan context. Little's (1999) work, focuses on the limitation of education opportunities in the plantations. It follows that improved education of the estate children will be essential for overcoming the social marginalization of the community.

Another report argues that changes happening in the estates, such as granting of citizenship, educational development, increased aspirations, social welfare development and media exposure encouraged the estate residents to search for human dignity and a new identity through an alternative settlement pattern different from line rooms (Technical Assistant Team, 1995). Furthermore, it is argued that settlement development creates a framework and conditions conducive for social development and integration.

Chandrasekara (2001) emphasizes the need for a sociological understanding of housing related issues in the estates. He asserts that the existing line rooms and related living patterns have failed to keep pace with the changing social aspirations of the plantation community. The social aspects of housing that require sociological attention are "privacy", "identity" and "recognition". Bastiampillai (1993) points out the need for elimination of social status duality between the Sinhalese villages and the estates in his proposals for integration between the estate and villages. A study conducted by the Marga Institute (1981) following the acquisition of Sri Lanka citizenship by the estate communities of Indian origin identified the need to rehabilitate these residents through provision of equal opportunities, ensuring 
them a satisfactory access to the national system, social and economic mobility and sharing equitably in the benefits of national development. Employing the term "integration", Nayak (2001) broadly considers the division between the Tamil and the Sinhalese people within a historical framework. He discusses to some extent the unfavourable social status of the minority ethnic groups. Daniel (1992) considers Estate Tamils as the third ethnic group of the country. Further, he states that the identity of these Tamils is shaped by life on the estates. Philips (2001) discusses the historical antecedents and structural parameters underlying the low status identity of the Plantation Tamils. The irony of the situation of the estate Tamils is concisely summed up by her statement, "For almost all of their history, the estate Tamils (Estate Origin Tamils) have been Sri Lanka's ethnic orphans."

Rapoport (1981) highlights the relationship between housing and social status based on various studies done in the United States. It sheds light on the specific area on which this paper focuses. Home ownership is very important in the personal life of a person. "The possession of a house offers a major physical object for use as an indicator of status and personal autonomy, and the house is an exchange value in so far as it is a commodity that can be bought and sold". Owning a house assures the status and autonomy of a person. Line room dwellers have neither autonomy nor ownership of the housing units they occupy. They have no other place to go to if the estate expels them.

\section{CONCEPTUAL AND THEORETICAL FRAMEWORK}

The estate system introduced by the British administrators, has a connotation of lower social status or disadvantage to the people who live and work in the estates. According to the Oxford Advanced Learner's Dictionary an estate is "a large area of land, usually in the country, that is owned by a person or a family" or "an area of land with a lot of houses or factories of the same type on it" (2000). The second definition especially applies to the British context and this meaning is really applicable to us since the British planters introduced the "estate industry" in Sri Lanka. An estate is a social stratum within the system of social stratification in Europe. Within these estates there were rigorous ordered boundaries and a special culture, in ancient Europe. The Tamil word "thurai" stands for lord, has become phonetically anglicised in the estate sector as "dorai" and the superintendents (periya dorai) and the assistant superintendent (sinna dorai) are identified through that term (Shanmugaratnam, 1997). This further supports the idea that the plantation structure created by the British involves a reproduction of the feudal, aristocratic system in Europe, which has a stratified structure. Max Weber (1864-1920) saw estate as a 'kind of community'. In his discussion of status groups, he uses estates. Weber identified the status positions as the effective claims to social esteem (Unwin Hyman Dictionary of Sociology, 1999). "Status positions confer both positive and negative privileges, and typically based on a special lifestyle and a formal training" (Oxford Dictionary of Sociology, 1998). A status group is "any group which can be identified in terms of specific, 'positive or negative, social estimation of honour' in a system of social stratification" (Unwin Hyman Dictionary of Sociology, 1999). Status is expressed and sustained through exclusionary practices such as marriages, conventions, customs, and common living arrangements. A collection of persons with a common status position shape a status group, which enjoys a common esteem (Oxford Dictionary of Sociology, 1998). Tamils of Indian origin do not have chances to integrate with the broader society outside the estates and they could not enjoy socioeconomic and cultural rights that are enjoyed by the members of mainstream society. The policies of British colonial rule prevented the integration or assimilation of immigrant Indian Tamils into broader Sri Lankan society. This resulted in Indian Tamils continuing to be a lower social status group compared with the other members of society. In this paper the estate community is considered as a separate status group with a negative (low status) social status within the broader Sri Lankan socio-cultural context.

The term status can be described as "a position the individual occupies in the social structure" in a very simple manner but it is also referred to as a basis of social stratification (Oxford Dictionary of Sociology, 1998). Sometimes social status is achieved through personal efforts, while it can also be a group characteristic. Ascribed social status is assigned to a person at birth or at different ages of his lifecycle. By social status, a person's general standing, vis-à-vis the other members in a society is implied here. In addition, social status carries with it the idea of superior and inferior positions within a system of stratification (Thompson, 1996). In this study, how a group of Tamils achieved a new social status and upward social mobility through a change in their housing will be explored. Concepts such as lifestyle, dwelling and living environment are used to study the social mobility of the selected estate residents. Status determines a large part of a person's social identity (Gelles, 1995). 
Nayak (2001) highlighted the importance of the concepts of "minority group" and "dominant group" in his discussion of the status of estate residents. Louis Wirth (1897-1952) defines minority as "a group of people, who, because of their physical or cultural characteristics are singled out from the others in the society in which they live for differential and unequal treatment, and who, therefore, regard themselves as objects of collective discrimination." Nayak (2001) states that "the presence of a minority group in a particular society has relevance in the context of the existence of a 'dominant group', which enjoys a privileged status in the society". It should be stressed that the Tamils in the estates felt that they do not enjoy equal social status to that of the Sinhalese community. They wanted to achieve an equal social status and overcome social exclusion. They tried to be on par with the majority ethnic group not through a form of violent struggle but through politics, labour movements and policy changes. Individual and group initiatives were made for upward mobility. The housing intervention of the government is a response to the group needs of the estate residents to achieve a higher standard of life and to live as equals to others in Sri Lankan society. This study sought to assess how far this intervention was successful.

Unlike classes, status groups have a quality of groups. They are determined by the distribution of social honour. A specific style of life is shared by a status group and the group itself is defined by social interaction within it. Economic assets can be a source of honour; however, similar class position does not necessarily create an identical status group. On the other hand, people from different economic classes may become members of the same status group, if they share a specific lifestyle. The way in which social honour is distributed in the community is called the status order. Criteria for entry into a status group may take form of kinship or certain level of education in some instances. The most extreme form of status groups with a high level of closure (strong restriction of mobility between statuses) was within the caste systems. Within the Hindu caste system, status distinctions are guaranteed not only by laws and conventions, but also by religious sanctions.

Social status can be discussed as a position as well as a rank (Labovitz, 1977). The current study pays much attention to social status as rank. The study focuses on the upward social mobility of the estate residents through the housing schemes. There are many perspectives that can be considered in the discussion of social status as a rank. The sociological perspective generally labels status as structural and treats status as rank, as one of the critical causal factors impinging on the individual or on the group. The high-ranking members possess more power, privileges, and prestige. Those who have more power become leaders and they participate in various group activities and do community work. They have a more positive image and ability to influence others. The social psychological perspectives put more emphasis on individual motives and perceptions. Social psychological studies concentrate on the motivation that leads a person to strive for higher status, or to study individual reaction to vertical mobility. The third approach treats status as rank and an important factor in interpersonal interactions (Labovitz, 1977). The current study incorporates selected components in all three perspectives.

\section{RESEARCH PROBLEM}

This study seeks to understand whether the change in dwelling alter the social status of estate residents. Dwelling includes not only the house but also the environment in which they live (setting). To study the main research problem, the following research questions were formulated. What are the socio-economic changes that took place after estate residents moved to the new settlement?, How do the settlers feel about their new social status?, How do the line room residents see the status change among the settlers?, How do the surrounding Sinhalese villagers perceive the changes?, Do the Sinhalese villagers accept that there is a status change among new settlers of plantation origin?

\section{RESEARCH METHODOLOGY}

Two research areas were included for the study covering the low and up country plantation areas in Kalutara and Nuwara Eliya. Basically the Nuwara Eliya district is a major tea planting area, while the Kalutara district is famous for rubber plantations. This study centred on two settlements meant for estate working families called Ganga Nagar in Nuwara Eliya and Jana Udana Gammanaya in Kalutara. Ganga Nagar is considerably old, whereas Jana Udana Gammanaya has been recently established. A selected group of estate workers have been given plots of lands and financial assistance to build their own houses on a self-help basis. In the 1980s, a group of the estate workers who lived in line rooms of Red Hill estate in Nuwara Eliya got half an acre plots of land and moved into a new settlement named Ganga Nagar established under the self-help housing project of the then government. In 1994 selected estate workers from Glandon Estate of Matugama took up residence in 
Jana Udana Gammanaya. These housing schemes are situated away from the existing line rooms and closer to the neighbouring Sinhalese villages. There are 28 houses in Jana Udana Gammanaya of Kalutara consisting of an equal number of Sinhalese and Tamil families; 14 houses belong to Tamils and the remaining 14 houses were offered to permanent Sinhalese employees of the estate. This village was inaugurated in 1997 and the settlement had been named by the then government. There are 40 houses in the Ganga Nagar settlement of Red Hill Estate (Nuwara Eliya). The recipients were given half an acre of land and the needed financial assistance was also provided by the government. There are five (05) Sinhalese families in Ganga Nagar settlement while the majority are Tamils.

The study was conducted from September 2002 to December 2003. Adequate time was spent in both locations in order to carry out a comprehensive study. Basically three categories of respondents were interviewed in the study. They are; line room dwellers, settlers and nearby Sinhalese villagers. This study employed a combination of quantitative and qualitative methods. Firstly, a questionnaire survey was conducted in both locations. All the persons in housing schemes of Ganga Nagar and Jana Udanaya Gammanaya were interviewed and also their relatives who lived in line rooms of the estates were covered in the first stage. Thus the survey sample composed of 54 line room dwellers including 31 in Nuwara Eliya, 23 in Kalutara and a total of 66 settlers consisting of 37 in Nuwara Eliya and 29 in Kalutara. Separate questionnaires were administered for settlers and estate residents. This step helped in understanding the general background of the area, social relationship patterns and areas for further research. These questionnaires were administered by trained Tamil speaking research assistants, who filled the questionnaires after lengthy discussions with the respondents. After that some families were selected for the qualitative studies from the line room dwellers and the settlers. A sample of the line room dwellers composed of 13 young persons ( 7 Nuwara Eliya and 6 Kalutara) and 10 adults (5 Nuwara Eliya and 5 Kalutara) while the sample in the settlement consisted of 10 youths (5 Nuwara Eliya and 5 Kalutara) and 13 adults (6 Nuwara Eliya and 7 Kalutara). In addition to these groups, an adequate number of surrounding Sinhalese villagers were interviewed to understand the difference between estate residents and the settlers. The sample from the Sinhalese villages included 43 persons, 23 from Nuwara Eliya and 20 from Kalutara. According to local folklore, Sinhalese villages that were around Ganga Nagar dates back to King Dutugamunu's period, while Sinhalese villages bordering Ganga Nagar were established four decades ago under government resettlement projects. In Kalutara, the Sinhalese villages close to Jana Udana Gammanaya have been there for more than 50 years according to the adults of the area. In-depth interviews, formal and informal discussions, participant and non-participant observations, comprised the qualitative study methods employed. Statistical Package for Social Sciences (SPSS) was used for analysing the quantitative data. Quantitative content analysis and qualitative in-depth content analysis were used to analyse the qualitative data. Variables such as the structure of the house, location of the housing scheme, pattern of dwelling, social identity, types of interactions, house and land ownership, living setting, facilities and lifestyle were covered in this study.

\section{DIFFERENCE BETWEEN “LINES” AND "SETTLEMENTS"}

Before discussing the research findings it is necessary to give a brief introduction about the two living places called "lines" and the "settlements". As Hollup (1994) pointed out, a "line room" is just a single room with an open veranda. The adjoining line rooms make up a row of housing units in a barrack building called a "line". Generally a long barrack building consists of 10-12 line rooms. A double line barrack building, with back-toback housing, can contain a maximum of 24 households (Hollup, 1994). A line room is the housing unit of an estate family. On certain occasions, the father, mother, adult sons and daughters and the grandparents and married members all live in the same room. Each room measures approximately 12 by 10 feet and is used by an entire family of sometimes more than five persons for sleeping, eating and living (Little, 1999). There is no adequate ventilation since the line rooms do not have proper windows. According to the Hindu agrarian practice of household hygiene, they apply a thin layer of cow dung on the mud floor. Walls are made using granite and the roof is constructed from corrugated iron sheets. The ownership of the building or land is not given to the family occupying the residence and in most of the cases they live in the line rooms for generations. The line rooms are situated in the interior part of an estate, at a distance from the surrounding villages. Red Hill and Glandon estates have similar patterned line rooms. There is no electricity in the line rooms of Red Hill but some of the line houses have electricity at Glandon. They do not have adequate latrine facilities and most of the latrines are not properly maintained. Neighbours share the available latrines. They are located more than 100 meters away from the line rooms. The living environment called settlements 
in the paper, are similar to a Sri Lankan village and are located close to the surrounding Sinhalese villages and the main roads. Though the recipients are given a common housing plan, they have built different patterned houses using the flexibility of the housing programmes. Most of the houses in Jana Udana Gammanaya and the Ganga Nagar have two or three rooms for sleeping, dining and living purposes and a separate kitchen. Each and every house owns a separate latrine and it is attached to the house in most of the cases. Some houses in Ganga Nagar have bathrooms as well. Houses have a cemented floor and a roof with tiles or asbestos sheets. Households in Ganga Nagar have half an acre of land while a household in Jana Udana Gammanya has only seven perches. Line rooms do not have such a specific portion of land but the residents have various sizes of plots of land by tradition. However, in most cases they do not have more than a small garden in front of the house. All the houses in the settlements have electricity and there are telephone facilities in some of the houses in Ganga Nagar. There are many household amenities in the settlement compared to the estate line rooms. The minimum market value of a house in Jana Udana Gammanaya is nearly one million rupees, whereas a house and plot of land in Ganga Nagar costs between one and a half million to twenty two million rupees. Estate residents could not sell the line rooms and therefore they do not bother about its financial value. There are an equal number of estate working Sinhalese and Tamil families who live in Jana Udana Gammanaya as a mixed settlement. Ganga Nagar is comprised mostly of Tamils except five Sinhalese families who also come from the estate lines.

\section{Socio-economic status of the respondents}

The estate sample at Kalutara (60.9\% male, $39.1 \%$ female) and Nuwara Eliya (54.8\% male, $45.1 \%$ female) contained both males and females. There is a good gender representation in both Jana Udanaya Gammanaya (55.2\% male, $44.8 \%$ female) and Ganga Nagar (54.1\% male, $45.9 \%$ female). There is more male representation in the sample of the Sinhalese villages in both Kalutara (85\% male, $15 \%$ female) and Nuwara Eliya (78.3\% male, $21.7 \%$ female). The age range of the respondents are $16-30(19.7 \%), 31-55(57.6 \%), 56-70(16.6 \%)$ and $71(6.1 \%)$ in the settlements. A similar age distribution could be observed even in the estates. There were 16$30(22.3 \%), 31-55(61.1 \%), 56-70(13 \%)$ and 71 and above $(3.7 \%)$ respondents in the estate sample. A quite significant number of respondents are drawn from the age group between 31 and 55 years. A higher proportion of estate respondents are employed (87\% Kalutara, 64.5\% Nuwara Eliya) compared to the respondents who live in settlements (69\% Kalutara, 24.3\% Nuwara Eliya). More unemployed respondents participated in the study from the settlements (13.6\% compared to $3.7 \%$ in estates). Majority of the respondents in the sample have got a formal school education and most of the estate and the settlement respondents are Tamil Hindus.

\section{CHANGING SOCIAL STATUS OF INDIAN ORIGIN TAMILS (IOT)}

Though the study sample includes Sinhalese families in Kalutara and Nuwara Eliya, this paper mainly focuses upon status changes of Tamil estate residents only. Furthermore, Sinhalese residents living in the settlements with Tamil neighbours have not experienced much differences in their identity when compared with estate Tamil people. Among them, Sinhalese settlers having kinship and other forms of ties with the traditional Sinhalese villages and the mainstream society, have more social power in the Sri Lankan society. Living in a village is not new to them, but for the line room residents it is a turning point in their lives. The changing social status of the Tamils will be analyzed by comparing it with the line room dwellers and the settlers, as well as the surrounding Sinhalese villagers.

\section{Status comparison between the line room dwellers and the settlers}

As mentioned in the theoretical discussion, there is a considerable relationship between social status and the pattern of dwelling. Gelles (1995) emphasized that a person's social identity is determined status largely. Each descriptive social identity is an evaluation, which imparts positive or negative status (Unwin Hyman Dictionary of Sociology, 1999). According to the discussion it was revealed that the settlers have a higher social status than that of the line room dwellers. The line room dwellers, settlers as well as the Sinhalese villagers in the sample have accepted this position. Line room residents in Glandon (78.3\%) and Red Hills (77.4\%) told that the settlers have higher social status compared to themselves. A small percentage of the line room residents (21.7\% in Glandon, 22.6\% in Red Hills) stated that both groups have a similar social status. All the settlers in Jana Udana Gammanaya and a majority of the settlers in Ganga Nagar (97.3\%) believe that they have a higher social status than that of those who live in the line rooms. The new social status of the settlers has given them confidence to maintain a sound relationship with the surrounding Sinhalese villagers. 
"Sinhalese community pay more respect to Tamils who live in the settlement. When Sinhalese people address the line room dwellers, they use terms such as "waren" (come), "palayan"” (go), "Demala", (Tamil), etc. But they do not use similar terminology when they address members of their own community" (Mahendran, A/L student, 17 year old Tamil youth, Jana Udana Gammanaya).

"Settlers have been much respected by the outsiders because they have more connections with the surrounding villages. We attend most of the functions of the Sinhalese villagers. And we too invite them for our functions. We too live like Sinhalese people. Tamils in the line room don't know how to live with Sinhalese community since they do not have a proper relationship with them. Line room dwellers get less respect from outsiders since they have no adequate experience of outsiders. Line room dwellers confine themselves only to the estate" (Anjali, 22 year, an unemployed Tamil girl studied up to GCE O/L, from Ganga Nagar).

It is very important for us to understand the perception of Sinhalese villagers on the social status of the people who live in settlements. In the qualitative study, a significant number of respondents $(91.3 \%$ Nuwara Eliya, $71.4 \%$ Kalutara) from the Sinhalese villages stated that the Tamils living in the housing schemes in both Nuwara Eliya and Kalutara, in close proximity to them, have a better social status than the line room dwellers and they give due respect to such settlers.

It is evident that the respondents categorize their situation, comparing it with "other" line room dwellers. Individualistic groups normally see the house as a status symbol critical to one's social or personal identity (Duncan, 1981). Again in the qualitative interviews, the majority of the line room dwellers (100\% Nuwara Eliya, $91.7 \%$ Kalutara) accept that the settlers have a high social status.

"Some of the estate labourers who went to Ganga Nagar think that they have reached a higher social status and try to show off. They do not like to attend to labour jobs anymore. Those who were used to selling bundles of firewood as their livelihood when they were in the line rooms, do not engage in it any further" (Devi, 48 year old Tamil woman, crèche attendant, Red Hill estate).

\footnotetext{
${ }^{1}$ Impolite word used to give a command to a lower status person

${ }^{2}$ Impolite word

${ }^{3}$ Impolite word
}

\section{Reasons for social status differences}

All three groups who participated in the study pointed out the reasons which affected the upward social mobility of the settlers. Among the reasons given, the most popular reason for settlers having a higher social status is the fact that the settlers had their own house and land. Respondents; $33.6 \%$ in the settlement and $37.2 \%$ in the estates believe that the settlers have a higher social status since they live in their own land and a house. The next important reason was that the settlers lived in a separate setting similar to a Sinhalese village $(15.7 \%$ settlement, $12.7 \%$ estate). Furthermore, $16.4 \%$ of the settlers believed that they were more civilized. The responses of those living in their own land and house, in a separate village like setting was similar to $50 \%$ of the responses given in the settlement and the estates of both districts. Adequate facilities (5\% settlement, 5.9\% in estates), the ability to lead a healthier life $(9.3 \%$ settlement, $5.9 \%$ in estates), modernized lifestyle (9.3\% settlement, $11.8 \%$ in estates) and a free and independent life $(9.3 \%$ settlement, $8.8 \%$ in estates) were important factors identified by both the line room residents and the settlers. Most of the factors pointed out relate to housing environment. On the other hand, nearly $17 \%$ of the responses from the line room residents and only $1.4 \%$ of the responses of settlers support the idea that both communities have equal social status, highlighting common issues of both groups such as; some settlers continue to work in the estates, represents the same ethnic group, financial difficulties and family problems. Settlers could have a free and independent life in the settlements unlike in the estates. Line room residents explained in detail, how they have suffered from the interventions of the estate officers and their drunken neighbours. They have not been able to socialize their children properly because of the activities of those who get drunk. Many of those who are drunk start quarrelling in the evening and the children are unable to study or even sleep.

The discussion on facilities focuses on electricity, telephone and easy access to main roads and shops. The findings of the study show that most of the people living in settlements have electricity. Only $55 \%$ of the line room dwellers have electricity, compared to $77 \%$ in the settlement. Furthermore, the remaining settlers have access to electricity and the delay in getting their connection is caused because of the personal problems of the settlers. About $84 \%$ of the houses in Ganga Nagar, and $69 \%$ of the houses in the Jana Udana Gammanaya have electricity whereas $44 \%$ of line rooms in Kalutara 
and $61 \%$ of the estate line rooms have the same facilities. One reason for estate residents not to get electricity or telephone facilities is the long distance between the main electricity and telephone wire lines that goes along the main roads, and the line rooms. Since this distance has been reduced in the settlements, they have been able to access electricity and telephone. This will be discussed in detail in the article.

Both settlements are very close to the main roads. Settlers in Jana Udana Gammanaya travel by bus to towns such as Kalutara and Matugama easily, while Ganga Nagar settlers travel to Nuwara Eliya, Gampola, and Pussellawa without much difficulty. They are close to hospitals, markets and government offices such as the village Grama Niladari's office (village level government officer), Divisional Secretariat (DS), Pradeshiya Sabha office (Local Government). Ganga Nagar is very close to Niltenna town, while Jana Udana Gammanaya is close to a small town called Kurulubedda. The Chairman of the Matugama Pradeshiya Sabha (local government), under whose jurisdiction this settlement is located and a member of the Western Province Council, live in this small town. Since settlements are located close to Sinhalese villages, the interaction between the Tamil and the Sinhalese communities have increased, causing an improvement in their social capital.

Tamils living in the estate line rooms cannot cut a jak, teak or any other tree or a fallen tree for their consumption even though they have planted them. The estate inhabitants say that estate officers cut down these trees and use them as they wish. However, in the settlements, they have the right to use these trees in their gardens. Line room dwellers cannot rearrange, add rooms to the existing line rooms without official permission, and there were some occasions when estate watchers broke unauthorised buildings in the estates. However, these prohibitions are not applied in the settlements. As was mentioned before, the Sinhalese villagers enjoy the freedom of managing their property as they wish. They can add new rooms or change entire houses, sell or buy without any objection as they have proper legal documents to prove ownership of the property. They have access to the government offices and an administrative body like the estate management has no control over them. All the Sinhalese villages have electricity facilities, while some villages even have telephone facilities.

There is a space between two houses in the settlement, unlike the single wall that divides two houses in the estates. Almost all the houses in the settlements have proper latrines, whereas a considerable percentage of the line room residents have no access to toilets. Most of the houses in the settlement have attached bathrooms or they have an idea to build a bathroom. In addition, they always tend to lead a modern lifestyle using modern equipment.

A considerable percentage of the family members in both settings are employed. Most of the family members in the settlements, Ganga Nagar and Jana Udana Gammanaya are engaged in outside, non-traditional occupations. As a result of their high income derived from outside jobs, they can afford to look after old parents and the other non-income earners in their families as well. This outmigration searching for jobs has become the current trend among the youth in most of the estates in Sri Lanka according to other studies too (Hettige and Piyarathne, 2004). Settlers in Ganga Nagar earn an extra income from their home gardens by cultivating tea, fruits and vegetables. However, this is not possible in the line rooms. In addition, they are able to do more poultry farming than the line room dwellers as they have sufficient space. Furthermore, it was observed that the settlers save more than the line room dwellers. The study findings show that a high percentage of the settlers save between Rs. $6000 /=$ and Rs. $12000 /=$ per month. This is related to the increased aspirations of the settlers followed by the housing intervention.

There are a large number of push bicycles in Kalutara than in any other area under consideration. One reason for that is the closeness of both settlement and estates to the main roads. The people in Red Hills have to bring their bicycles down almost $2-3 \mathrm{~km}$ from the hills. This difficulty has forced them to buy motorbikes. Since Ganga Nagar is a more established settlement, they have the highest number of Television sets. Most of the families who own Television sets also have VCD players and video decks. Three houses were using satellite antennas to watch more TV channels. Settlers often keep their valuable household amenities in the living room. The study shows that the settlers have more household amenities such as radios, televisions, cassette recorders, sewing machines, telephones/ mobile phones, cushion/ plastic settees, fans, refrigerators and motor bikes in the houses of the settlements. Furthermore, they have kept the houses in such a way that automatically encourages outsiders to interact with them, unlike in the line rooms. The living rooms have been described by sociologists as "the room most accessible to outsiders" and therefore "a window to the outside world", and "a medium of conspicuous consumption", a deliberately managed backdrop for the presentation of the self and an objective indicator of socio-economic status (Duncan, 1981). The 
"windows to the outside world" are more positive in the settlement than the "gloomy line rooms".

In general, a high percentage of estate family members have studied up to Grade Five. The majority of them do not study beyond that because of various socioeconomic constraints. At other levels, family members in settlements are in the forefront. It may be because of the fact that they have a good environment to study in, unlike the congested and noisy line rooms. In addition, the settlement culture is highly conducive to the educational attainment as a means of upward mobility. Therefore, their pursuit of education is more successful. On the other hand, families who were eligible to get land were in a higher socio-economic position than when they came to the settlements. These circumstances have compelled them to move out from the estates. Most of the estate dwellers send their children to estate schools. There is a school in the middle of Red Hills which has classes up to Grade Nine. The number of students and staff is small. The principal of the school stays in the school quarters with his family. He has many difficulties since the school is situated on the top of a mountain in the Red Hill estate. His family has to come down nearly one and a half kilometres to reach the Niltenna town. Some of the publications on estates also say that the level of education is significantly low. Most of the children that live in the settlement, attend schools in the cities and adjoining small towns. When comparing research findings related to education, it is clear that the Sinhalese villagers have a higher percentage of educated people. It was also clear that most of the settlers and Sinhalese villagers considered education as a way of vertical mobility for their families. The education level of the respondents show the above educational attainment trend by family members. $16.7 \%$ of respondents in the settlements and $46.3 \%$ of respondents in estates have received school education between Grades one to five. However, the level of education of the respondents from the settlements is high. $27.8 \%$ of estate respondents and $59.1 \%$ of respondents from settlement have studied between Grades six and eleven. Children of some of the villagers are not of the school going age and they too are included in the no schooling group, which is a little misleading. Compared to the estate families, families in the settlement spend a lot on education. The expenses on education by estate dwellers are relatively lower in both districts.

As the settlers have a high income as a result of adopting a new lifestyle, it appears that their expenses on education, clothes, entertainment, medicine is relatively higher compared to that of the line room residents.
Settlers seem quite sensitive to illnesses and they spend a higher percentage of their income on medicine. They are relatively more advanced than the line room dwellers, therefore their health awareness is higher, and they tend to spend more on medicines. They do not patronise the estate dispensary. Families in Jana Udana Gammanaya and Ganga Nagar are not entitled to get medical facilities from the estate health centre and they cannot claim for health related expenses from the estate, whereas entire families of the estate workers who live in estate line rooms are eligible to get free treatment from the estate medical officer. This does not mean that the estate medical facilities are adequate but the available facilities are sufficient only for the daily illnesses of the estate community.

Villagers of the surrounding Sinhalese villages in Niltenna and other close villages of Ganga Nagar and neighbouring Sinhalese villages in Kurulubedda, Kuda Gama of Jana Udana Gammanya shared similar viewpoints as the line room residents and the settlers. According to them settlers have more integration with Sinhalese community, since they live closer to Sinhalese villages. When Tamils lived in lines far away from Sinhalese villages before coming to the settlements, they did not come to the Sinhalese villages often and were not familiar with the Sinhalese traditions. However, now most of the Tamil members in the settlement have a chance to associate with Sinhalese neighbours. At the in-depth interviews with line room dwellers (72.7\% Nuwara Eliya, 83.3\% Kalutara), settlers (100\% Nuwara Eliya, 72.7\% Kalutara) and the Sinhalese villagers (47.8\% Nuwara Eliya, 61.9\% Kalutara), it was agreed that the people who possess "good" qualities have a better social status. All the respondents said that those "good" qualities are found in settlers unlike in the line room dwellers. They do not drink alcohol regularly; do not quarrel as a result of a changed and modernized lifestyle.

\section{"Settlers in Jana Udana Gammanaya try to lead a decent life. They do not shout as when they were in estate lines. There is a saying in Sinhalese "demalu padi gatta wage" (Like the Tamils' pay day; it is assumed that Tamils consume alcohol and shout on their pay day). "Demalu wage ke gahanawa" (shouting like Tamils). However, these sayings are not valid anymore in the settlement" (Seelawathie, a 35 year old Sinhalese lady, Sinhalese villager, Kalutara).}

The above statement is more than adequate to prove the high status that "settlement Tamils" have projected so far. A considerable percentage of Sinhalese respondents 
in Nuwara Eliya (30.4\%) and Kalutara (66.7\%) say that the settlers have decent behaviour compared to the line rooms. The estate has a specific culture that shapes the behaviour of the line room residents. The majority of them drink, quarrel, beat their wives, punish their children severely and there is a lack of proper health practices and almost all the line room dwellers lead similar lifestyles. However, the environment in the settlement differs in certain ways such as, each family tends to have their own lifestyle, there are unique, different houses, they try to be decent, attempt to develop more, earn more, give a better education to their children and send them to better jobs. When they live in the estate, it is a homogeneous community economically, socially, and they are not open to the outside world, but the settlement is open to the outside world and closer to the Sinhalese villages. The thesis of the Culture of Poverty introduced by the American Sociologist Oscar Lewis (1914-71) can be applied in this context. "It is a cultural milieu characterised by fatalism, resignation and idleness, which is antithetical to achievement, hard work, and self-reliance and tend to be passed on between generations" (Unwin Hyman Dictionary of Sociology 1999). Settlers in these two schemes believe that they have same social prestige to that of the Sinhalese community in surrounding villages. Rokoff stressed the "meaning" which owners attach to their houses. This is the first time they get an opportunity to control their own private "space" and it gives them a feeling of freedom. When they were in the line rooms, they were not allowed to add a new room, build a kitchen, or cut a tree that they planted without formal permission from the estate officers. They had to get permission from the estate officers for almost all the activities. Estate officers often threaten those who do not accept the interferences of the staff, saying that they would be expelled from the line rooms. This method of control has existed in the plantation sector from the colonial era of British planters. The settlers felt that by being in control of their own private space, they had the power and opportunity to make something of themselves, to be "more of an individual", to achieve a kind of self-fulfilment and to get an assessment about their high status social identity. This situation brings the settlers a new dignity, a social status and recognition in the society. They are in control of projecting a high status social identity as autonomous individuals and replacing the weaker aspects of it.

Any group with a positive or negative social honour or prestige can be considered as a status group. Settlers and the line room dwellers were asked which group gets more respect from the Sinhalese villagers (broader world) in the vicinity. It is an indirect way of understanding whether the Sinhalese community accept that the settlers are having a higher social status. This way of questioning assures the social mobility of the settlers. Both settlers and the line room residents agreed that the settlers are more honoured by the Sinhalese persons in the surrounding villages. Nearly $87 \%$ of the line room residents and $100 \%$ of the settlers in Kalutara agreed that the settlers get high respect from the outsiders. There is a similar pattern of response even in Nuwara Eliya. For about $83.9 \%$ of line room residents and the $97.3 \%$ of settlers accepted that the settlers are more honoured by the surrounding villagers. Sinhalese people who participated in the in-depth interviews in Kalutara (71.4\%) and Nuwara Eliya (91.3\%) explained that they give higher respect for the settlers than for the line room residents. It is really a positive factor for the sustainability of the achieved social status of migrated Tamils. It is interesting to note the causes identified by both the estate residents and the settlers of how settlers can gain a higher social status from the outsiders. Similar reasons pointed out in the above discussion are also observed here. Line room respondents $(24.8 \%)$ said that they do not have their own houses and land separately, whereas settlers own plots of land and houses. Settlers (27.1\%) support this idea. Tamils who moved to the housing scheme live in a different setting that is similar to Sinhalese villages. This too helped in getting high respect for settlers from the outsiders according to the settlers and the line room residents $(16.5 \%)$. Settlers have more facilities $(8.3 \%$ estate residents, $5.5 \%$ settlers), lead modern lifestyles (6.4\% estate residents, $9.3 \%$ settlers). Settlers integrate better with Sinhalese society compared to the line room residents ( $7.3 \%$ estate residents, $28.6 \%$ settlers). Settlers need more money to build better houses and for other infrastructural developments. Therefore, they always try to develop more (10.1\% settlers). Settlers could lead a free and independent life without anyone's interference, whereas the estate residents $(7.3 \%$ line room residents, $3.1 \%$ settlers) do not have such freedom. Settlers could enjoy better infrastructural facilities and it resulted in a healthier lifestyle $(6.2 \%$ settlers $)$, whereas the estate residents could not enjoy such a healthy lifestyle. The autonomy of a person or a group depends on the status of a person (Rapoport, 1981). That situation prevails in the new settlements. It is evident that the settlers could gain high respect from the surrounding Sinhalese villagers when they live in separate dwellings and a setting in contrast to the line rooms.

The Tamils who migrated to the settlement from the line rooms tend not to respect line room residents, some of whom may be related to them. It was observed that there is a hierarchy between the settlers and the line room 
residents. This study explored the views of settlers and line room residents with regard to each other. Estate residents (91.0\% Nuwara Eliya, 66.7\% Kalutara) feel that the settlers do not respect them. A considerable percentage of the settlers (66.7\% Nuwara Eliya, $72.7 \%$ Kalutara) also accept the above grievances of the line room dwellers. Sinhalese respondents too observed that the settlers (78.3\% Nuwara Eliya, $42.9 \%$ Kalutara) looked down upon line room dwellers. An interesting finding is that there is a status ranking between the line room residents and the settlers, although the settlers originally came from the very same line rooms. According to line room respondents (100\% Nuwara Eliya, 75.0\% Kalutara), Tamils in the line rooms presently started showing higher respect to the Tamils in the settlement. Almost every one of the settlers who participated in the in-depth discussions accepts this situation.

\section{"When settlers come to line areas, even for a short visit, the line room residents respect them. They deserve it because the settlers live in their own house and a plot of land unlike us" (Murugan, 58 year old Tamil man, estate Kangani, Red Hills).}

The above statement shows how the ownership of properties gives a higher status to the settlers. There is a growing number of literature indicating that the nature of housing is a key determinant of social status (Agnew, 1981). Sinhalese respondents in the surrounding villages (60.9\% Nuwara Eliya, 38.1\% Kalutara) also observed that line room dwellers give higher respect to settlers. This situation must be understood in the context of the differences between the housing structures, lifestyles etc. discussed above.

\section{Comparison of Social Status between the settlement and the surrounding Sinhalese villages}

In general, Sinhalese neighbours do not give much respect to people who live in line rooms as was discussed in the literature review. In some cases, the Tamils are not welcomed from the front door of Sinhalese houses, but from the back door. Tamils too do not try to sit with the Sinhalese persons, and argue with them and so on. However, they have been demanding equal status for generations peacefully, unlike the militarised Tamil groups in the northern and eastern parts of the country. Both estate residents $(83.3 \%)$ and the settlers $(66.7 \%)$ feel that the settlers and the surrounding Sinhalese villagers are enjoying equal social status. A noticeable percentage of the settlers $(33.3 \%)$ and the line room residents $(16.7 \%)$ also said that the settlers do not have an equal social status like that of the Sinhalese community. To crosscheck the above answer of the respondents, the settlers were asked whether they feel their social status as a group is lower than the people living in the surrounding Sinhalese villages. Nearly $76 \%$ said that they don't feel at a lower status compared with the Sinhalese villagers, while $24 \%$ accepted that they have a lower social status. In this question too, most setters stated that they have equal recognition in the area. This indicates an improvement of the social status of settlers compared to the line room residents. Harassments, checking, arrests and suspicions, during the internal conflict between the Liberation Tigers of Tamil Eelam (LTTE) and the Government of Sri Lanka (GOSL), too had contributed significantly to the feelings of unequal status of Sinhalese and Tamil communities during the time of this study. Henri Tajfel (1919-1982) and his associates argue that such positive evaluations are made on a comparative basis. "When our group does better than another group we nourish positive selfidentities" (Drigotas, Iunsko and Scholar, 1998). The Indian Origin Tamil (IOT) community has been yearning for a favourable social status and they have achieved it to some extent, at least through the housing interventions. They considered housing, land ownership and the setting as barriers for them to have a satisfactory social status. Almost similar reasons are given by the settlers, line room dwellers and the Sinhalese villagers to substantiate the argument. Line room residents said that they live in a different setting to that of the Sinhalese villagers, but have observed that the Sinhalese villagers and the settlers who are residing in a similar living setting $(6.6 \%$ line room residents, $7.3 \%$ settlers) have their own house and land (22.8\% line room dwellers, $24.5 \%$ settlers). This is in keeping with the literature from other countries, highlighting the role of housing in social status and identity formation (Rapoport, 1981). Settlers (22.7\%) have adopted a lifestyle similar to the Sinhalese persons in the settlement (9.6\% line room residents). Furthermore, the similarity of the lifestyle was highlighted in the areas such as design of the houses, furniture and household utensils, education of the children, means of income, access to small towns, expectations, hobbies and dressing. Factors such as lack of facilities (19.1\%), not having a free, independent life (5.9\%), lack of wealth (11.8\%) and indecent behaviour (3.7\%) have impacted the low social status of line room residents. However, they felt that the settlers have gained in all these aspects by moving into Ganga Nagar and Jana Udana Gammanya. However, Settlers think that the Sinhalese community live better than them. Factors such as higher income (17.3\%) and ethnic differences $(7.3 \%)$ and the fact that the Sinhalese villages get more government support, helped to develop the idea that the settlers do not have equal social status as that of the majority Sinhalese community. This situation 
has arisen because of the unequal link of Sinhalese and Tamil villages to the mainstream society in general and to the government institutions in particular. This is one of the vital issues that should be taken into account when developing national policies.

Most of the respondents living in the settlement believe that they live in a village atmosphere similar to Sinhalese villages in the surrounding area and have higher social status and recognition than those in the line rooms. Tamil settlers are keen to have contacts with the Sinhalese people unlike the line room dwellers. Generally in the Sri Lankan context, Tamils believe that they do not have enough recognition or respect and that they are secondclass citizens and have no citizenship by birth. In contrast to the established pattern of thinking, line room dwellers (100\% Nuwara Eliya, 91.7\% Kalutara) mentioned that the Sinhalese villagers and Tamils in the settlements have equal social status in the qualitative study. All the settlers also endorsed it in the in-depth interviews conducted with them. Sinhalese villagers (87.0\% Nuwara Eliya, $100 \%$ Kalutara) agreed that the settlers think that they are equal in status to Sinhalese neighbours. On the other hand, the opinion of a considerable number of Sinhalese respondents (69.6\% Nuwara Eliya, $85.7 \%$ Kalutara) is that they and the settlers are similar in status. Mahesh, a Sinhalese young man, perceived this situation using more practical indicators.

"Line room dwellers call us "Mahattaya" (sir), "Aiya" (meaning is informal "sir"). They respect us more. But the settlers call us by our names as our own people call us in the Sinhalese area. Though it is a little painful to me, it is a good trend" (Mahesh, 20 year old Sinhalese man, Teacher, Niltenna).

The following case shows the difference in social respect for a family who moved to the settlement. A lady from Ganga Nagar compares their estate life with settlement life:

"My husband lived in the estate line room with his parents. There also we had high respect since my father-in-law is a Kangani and my husband's family members are educated. But, I feel that we get more respect after migrating to the settlement. Some of my husband's classmates still live in line rooms and work in the estate. As a result, they are discriminated and are not respected by the outsiders. All the Tamils get a considerably higher social status after coming to Ganga Nagar. My children learn in one of the best schools in Kandy and associate with friends coming from high-class backgrounds. At that time all my children's classmates have embarrassed them by questioning, "Why do you live in a line room?". We were under stress and the children also worried a lot. Some of my best friends visited us when we were in line room. Even though they commented on nothing, we felt uncomfortable. Today we are using our new address. We can proudly give our address to anyone as Ganga Nagar residents, unlike the Red Hill dwellers" (Anila, 42 year old housewife, Tamil, Ganga Nagar).

As stated by other researchers too, home ownership is an important factor in the "prestige scale", based upon consumption. Some other researchers provide evidence for the concern with the home as their personal autonomy (Agnew, 1981). Line room residents (100\% Nuwara Eliya, 83.3\% Kalutara) say that the people who own a house, land and other properties are well respected by the society.

"Tamils in the settlement try to boast often about their social status. They always highlight that they own a house and land unlike line room dwellers. By highlighting these differences they show that they have a high social status" (Gopalan, CWC union leader, 40-year-old man, Rubber Tapper, Glandon estate- Kalutara).

Each and every respondent from the settlement agreed with the above idea of the line room dwellers. A significant number of Sinhalese villagers too held the same view. Almost all the settlers in both districts believe that they are well respected by Sinhalese villagers than the line room residents, though some of them thought that they do not have equal social recognition of the mainstream Sinhalese. In the qualitative study, a significant percentage of respondents (91\% Nuwara Eliya, $75 \%$ Kalutara) from the estates also agreed that the Sinhalese men and women respect settlers more than the line room dwellers. Sinhalese persons observed that they are not getting the same level of respect from the two groups of Tamils. Sinhalese respondents in Kalutara (28.6\%) and Nuwara Eliya (60.9\%) said settlers do not respect Sinhalese people like line room people and a considerable percentage of Sinhalese persons who participated in the in-depth interviews in Kalutara (19\%) and Nuwara Eliya (69.6\%) stated that line room dwellers respect Sinhalese persons more than settlers. This again proves the thinking of Tamils in the settlement, since they perceive themselves as equals with the Sinhalese neighbours and do not show any deference to Sinhalese community. 
Agnew (1981) discusses home ownership and identity. He has paid attention to two aspects. Firstly, the link between home ownership and the practice of personal life. Secondly, the relationship between home ownership, the personal life and the growth of local or community consciousness. According to our findings, it is clear that the consciousness as settlers and the lifestyle of the settlers have improved and it has helped them acquire a new social status and identity. People do not experience life in the abstract context of a 'mass society'. Their knowledge is acquired and they live their lives in the context of 'social worlds' dominated by the perspectives of different 'reference groups', the meaning of which is attributed to acts and events through communication and interaction with a limited number of people. In everyday life, such social worlds provide the setting for definition of material needs and the identification of status objects (Agnew, 1981).

In the qualitative study, almost all the line room residents and the settlers revealed that they would get lower social recognition or respect from the others if they revealed their line room identity. All the line room residents and settlers felt that they can get a better social status if they move to a housing scheme. They are very eager to move into a separate, spacious house, ending their line room life. In the in-depth interviews, both settlers and the line room respondents revealed that the Tamils in the lines are trying to change their social status through various individual initiatives. Line room dwellers (67.3\% Nuwara Eliya, 41.7\% Kalutara) and the settlers (91.7\% Nuwara Eliya, 63.6\% Kalutara) felt that the government officers attend to the needs of the settlers more than the line room dwellers, because they immediately take into consideration their higher social status.

The perception of the outsiders about the living environment of the new settlers is also crucial in this discussion. The Tamils as well as the Sinhalese persons call Ganga Nagar as a Colony. The term Colony is significant in this discussion, because there are so many colonies meant for Sinhalese society in the area. Due to the Mahaweli irrigation development scheme, the Sinhalese villagers were settled in newly established colonies in Niltenna and closer areas in order to create space for the reservoir. Therefore, the Tamil settlers in Ganga Nagar also have acquired the same social prestige as the Sinhalese people by living in a colony. The Sinhalese as well as the Tamil people also address Jana Udana Gammanaya as Gammane. The term Gammane denotes Sinhalese village. Since it is mostly a mixed village, the people in Jana Udana Gammanaya also acquire high prestige similar to Sinhalese villages of the area. These factors gave the settlers a higher social status. They gave the above reasons to support the fact that they also have the same social status as the Sinhalese villagers. The above data clearly shows that the settlers have high self-esteem, recognition and project it to the "outsiders". Self-esteem plays a key role in intergroup relations. We can gain self-esteem by comparing ourselves with others in our group or by seeing ourselves as a member of a prestigious group. A group gets its prestige when group members compare their group with a reference group of higher status, in order to define their group and see themselves in a positive light. Self-esteem allows one to see how people might try to change existing inter group relations in order to address self-concept concerns. As a result of the establishment of the housing scheme, the Tamils who moved to new houses adopted a different social status and this provided a favourable background for them to have better integration with the neighbouring Sinhalese villagers. The Sinhalese and the Tamil residents in the area use the term Gammanaya, which they often use to refer to Sinhalese villages, to address the new settlement in Kalutara. There is a clear difference between the people who live in line rooms, who are known as Layime Aayo, Watte Aayo, and the people from the settlement who are called Game Minissu, or Gammane Minnissu. In Nuwara Eliya, the surrounding villagers used the terms such as Kani, Colony, and Niltenna to identify the Ganga Nagar. There are two types of Tamils, settlement Tamils and estate Tamils or line room Tamils. The people of the area categorized or grouped the same Tamil community into two according to their dwelling patterns. The identities could not be measured adequately in isolation. Comparing identity with others is natural. The new identity of the settlers brought them a better social status and vice versa. At this juncture there is no need to have a broad discussion on social identity and the extent of the earlier discussion is enough to understand the new social prestige of the Tamils in the settlement. Devaraj (1984) states that the Sri Lankan consciousness includes the recognition of the multi-ethnic nature of our society and transcending these differences could be strengthened only by a due recognition of the rights and status of the different ethnic groups and ensuring mutual equality and mutual respect among them (Devaraj, 1984) This situation can be seen as an emerging trend according to the study.

The social identity theory of Tajfel is based upon the assumption that we all have a need for a favourable selfidentity. Furthermore, he states that the status of groups to which we belong helps us to achieve positive selfidentity (Drigotas, Iunsko and Scholar, 1998). The above research findings clearly reveal how Indian Origin Tamils 
achieved a higher status as settlers. He has further said that the positive self-identities are established through comparison with other groups. If our group understands that we do better than other groups, we would have a positive (strong) identity. This again has been proven in the above discussion, because the settlers have compared their situation with the line room dwellers, and the surrounding villagers. The Tamils who live in Jana Udana Gammanaya gain higher respect since they live with Sinhalese residents in a mixed village. It can be well understood when it is compared with their previous setting (line rooms). Now no one would call them watte eka, Layime eka (person from lines, person from estate). In contemporary western culture, individual identity is paramount so that the psychological concept of self-identity and self- esteem are seen as linked and as focal in social, personality, developmental and clinical psychology (Rapoport, 1981).

\section{Are settlers and line room residents proud about their "dwellings" and "housing environments?"}

In the in-depth interviews, over $61 \%$ of the line room dwellers in various divisions of Glandon estate in Kalutara stated that they were not proud about their residence. Most of the line room respondents (54.5\% Nuwara Eliya, 58.3\% Kalutara) explained various stories that showed their feelings of shame about living in estates. Settlers (58.3\% Nuwara Eliya, 81.8\% Kalutara) too faced such embarrassing situations before they moved into a settlement. Settlers in Kalutara (96.6\%) and Nuwara Eliya $(97.3 \%)$ are very proud of being in the settlements. Feelings such as we live in our own separate, spacious, houses and lands (55.4\%), we are living in a village and starting a new life $(30.3 \%)$ are the reasons which have made them feel even more proud. According to the ideas of John Agnew, firstly the possession of a house offers a major physical object to use as an indicator of status and source of personal autonomy and secondly, the house has an exchange value as a commodity that can be bought and sold. This idea has been proven by this study.

As a whole there are two social statuses in the country; one is more dominant (positive) and the second is the negative or unfavourable social status. According to the study, the Plantation Tamils moved into the second social status which is favourable for them through the housing scheme. They would not have been able to move into the favourable social status if the housing scheme was not there.

There are various housing interventions in the privately owned estates, as well as the estates owned by big

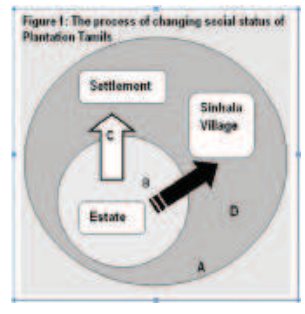
A Prestige (positive) social status
B Negative social status
C Housing intervention
D No voluntary direct mobility

companies in the Nuwara Eliya and Kalutara districts, but it is difficult to see this sort of positive result in those housing interventions. For example, there is a housing intervention to build two storied housing schemes in the middle of the estates, replacing the existing line rooms. People living in the line rooms will get better facilities through this scheme. However, there are no changes in the status of the Tamils in these schemes similar to the situation seen in the housing schemes discussed earlier in this paper. Furthermore, the aforementioned housing schemes are a restoration of the existing dwelling patterns of the line room dwellers according to the views of the people who live in those housing schemes. In some of the low country estates, the estate owners have built better houses in those estates, but the dwellers are not given ownership. On the whole, interventions of this nature have caused Tamil labourer families to be more under the control of the estate authority.

\section{CONCLUSION}

According to the study, housing schemes have played a significant role in creating a new social status for the migrated Indian Origin Tamils and integrating them with the larger Sri Lankan society. The study has shown the upward social mobility of the segment of IOT settlers from three perspectives; the Sinhalese, line room dwellers and the settlers. This facilitates them to enjoy a favourable social status and self-esteem, who previously lived in far away places from the Sinhalese villages. Living in these newly established schemes have provided a base for better social integration. Changing the dwelling has paved the way for a group of Tamils who lived in line rooms previously, to come to settlements and have closer interactions with Sinhalese ethnic majority. Though a group of Sinhalese residents live in the settlement of Kalutara, there is no significant social status change among them, as they enjoy a lot of the privileges being members of the ethnic majority. This type of micro level studies would support in understanding and solving the ongoing macro level issues such as the ethnic conflict, since some have interpreted it as status based identity conflict. Government and non-governmental organizations (NGO's) have to think carefully before initiating these 
types of development activities, because other ethnic groups should not feel that one ethnic group is favoured over the others. Otherwise this misunderstanding would disturb the ethnic harmony of the area. There should be a close monitoring procedure to make sure that the planned objectives of the project are achieved. If these housing schemes are established as mixed villages like Jana Udana Gammanaya, they will provide more opportunities for interactions, understanding, sharing, forming emotional bonds and ensuring co-existence between the Sinhalese and Tamil communities. The mixed settlement would give more social prestige for the Tamil community than the homogeneous Tamil settlements. However, even the homogeneous settlement created differently to the line room setting deserves higher social honour similar to the case of Ganga Nagar. The study shows that physical proximity has caused emotional attachments. On the other hand, the achieved social status of the Indian origin Tamils facilitates closer relationships with the Sinhalese community. In other words, Sinhalese men and women are encouraged to have more interaction with the Tamils through the newly achieved social status acquired through the settlement. In the long run, there is better ethnic re-socialization between children and adults of the two ethnic groups (communities) within the settlement and this would certainly promote ethnic harmony and nation building.

\section{References}

1. Agnew, J., 1981. Home Ownership and Identity in Capitalist Societies. In: J.S. Duncan, ed. Housing and Identity. London: Croom Helm Ltd., pp. 64 78 .

2. Bandarage, A., 1950. Colonialism in Sri Lanka: The Political Economy of the Kandyan Highlands 18331886. Berlin: Mouton Publishers, pp. 1-2, 280-286.

3. Bastiampillai, B., 1993. Plantation - Village Integration: a Need for Ethnic Harmony. In: G. Moonesingha, ed. Sri Lanka; Towards Nation Building. Colombo: Shramaya Publication.

4. Chandrasekara, D. P., 2001. Housing and Settlement Development. In: H.E.B. Kamphuis \& B. Sivaram, ed. Human Perspective in the Plantation Sector. Battaramulla: Programme Support Group, p. 58.

5. Daniel, V.E., 1992. Three dispositions Towards the Past: One Sinhalese, Two Tamil. Colombo: Studies in Society and Culture: Sri Lanka Past and Present in Association with the National Libraries of Sri
Lanka., p. 3.

6. Dayaratne, R., 1999. Sociological Perspective in Settlement Development. In: The Plantation and Social Welfare Trust \& The Programme Support Group, Consultative Forum on Human Settlement Development in Plantations. Colombo, 10 November 1999.

7. Devaraj, P., 1984. Indian Tamils of Sri Lanka-Identity Stabilization and Inter Ethnic Interaction. In: Social Scientists' Association, Ethnicity and Social Change in Sri Lanka. Colombo, December 1979.

8. Drigotas, M.S., Insko, C. \& Schopler, J., 1998. Mere Categorization and Competition: A Closer Look at Social Identity Theory and The Discontinuity Effect. In: S. Worchel, M.J. Francisco, D. Paez \& C.J. Deschamps, ed. Social Identity: International Perspective. London: Sage Publications, p. 181.

9. Duncan, S. J., 1981. Housing and Identity: Cross Cultural Perspectives. In: J.S. Duncan, ed. Housing and Identity. London: Croom Helm Ltd., p. 3.

10. Duncan, G. N., 1981. Home Ownership and Social Theory. In: J.S. Duncan, ed. Housing and Identity. London: Croom Helm Ltd., p. 120.

11. Gelles, J. R \& Levine, A., 1995. Sociology: an introduction. New York: McGraw-Hill, p. 159.

12. Hettige, S.T \& Piyarathne, A., 2004. A Sociological Analysis of Factors that Discourage Youth to Take Up Plantation Work. Colombo: Plantation Human Development Trust (PHDT) (Unpublished consultancy research report).

13. Hollup, O., 1994. Bonded labour: Caste and Cultural Identity among Tamil Plantation Workers in Sri Lanka. Colombo: Charles Subasinghe and Sons, pp. VI, 53.

14. Jayaweera, S., 1991. Women in the Estate Sector. Colombo: Center for Women's Research (CENWOR).

15. Jayaweera, S. \& Sanmugam, T., 1993. Women in the Rubber Sector in Sri Lanka. Colombo: Center for Women's Research, p.5.

16. Labovitz, S., 1977. An Introduction to Sociological Concepts. New York: John Wiley and Sons, pp. 134, 156-157. 
17. Little, A., 1999. Labouring to Learn: Towards a Political Economy of Plantations, People and Education in Sri Lanka. London: Macmillan Press, p. 50 .

18. Malwatte, H., 2000. Social Development. In: B. Sivaram, ed. Plantation Management in New Millennium. Colombo: National Institute of Plantation Management, p. 404.

19. Manikam, P.P., 1995. Tea Plantation in Crisis: An Overview. Colombo: Social Scientists' Association, p. 51.

20. Moonesinghe, Gnana, 1995. Sri Lanka: Towards Nation Building. Colombo: Shramaya Publications, p. 64 .

21. Nayak, S.C., 2001. Ethnicity and Nation Building in Sri Lanka. Delhi: Kalinga Publication, pp. 32-37.

22. Oxford Advanced Learner's Dictionary, 2000. 6th ed. Oxford: Oxford University Press.

23. Oxford Dictionary of Sociology, 1998. Oxford: Oxford University Press.

24. Peiris, G.H., 1996. Development and Change in Sri Lanka: Geographical Perspective. Kandy: International Centre for Ethnic Studies.

25. Philips, A., 2001. The Dilemmas of Identity Construction: Gender, Space and Ethnicity among the Estate Tamil. In: R. Philips, ed. Sri Lanka: Global Challenges and National Crisis. Colombo: Social Scientists’ Association, pp. 217-221.

26. Piyarathne, A., 2004. Impact of Poverty Alleviation Projects on Plantation. In: R. Asiriwatham \& P. Thalaysingham, ed. Poverty and Conflict in Sri Lanka: Integrating Conflict Sensitivity into Poverty Analysis. Colombo: Centre for Poverty Analysis.

27. Piyarathne, A., 2004. Setting, Space, Prestige and National Integration. In: Sri Lanka Foundation Institute, Annual Convention on Constitutional Reforms \& National Development, Colombo, 10- 11 December 2004.

28. Piyarathne, A., 2004. A Sociological Analysis of Occupational Crisis among Youth in the Plantation Sector in Sri Lanka. In: Faculty of Humanities and Social Sciences, of the Open University of Sri Lanka,
The annual academic sessions. Colombo, December 2004.

29. Piyarathne, A., 2005. Wathukaraya Kamkaruwa Ha Wenaswana Jeewana Ratawa. (Plantation, Worker, and Changing Livelihoods). Colombo: Wijesooriya Publishers.

30. Technical Assistant Team, 1995. Housing and Settlement Development on the Estates: a Proposal for New Implementation Strategy. Colombo: Plantation Human and Social Welfare Trust.

31. Presidential Secretariat, 1996. Presidential Committee to Investigate in to and Make Appropriate Recommendations on Socio-cultural Problems in the Plantation Community with Special Focus on Youth. Colombo: Presidential Secretariat.

32. Rapoport, A., 1981. Identity and Environment: A Cross-Cultural Perspective. In: J.S. Duncan, ed. Housing and Identity. London: Croom Helm Ltd., pp. 11, 74-75.

33. Sarup, M., 1996. Identities, Culture and the Post Modern World. Athens: The University of Georgia Press.

34. Shanmugaratnam, N., 1997. Privatization of Tea Plantations (the Challenges of Reforming Production Relations in Sri Lanka: An Institutional Historical perspective). Colombo: Social Scientists' Association, pp. 40-45.

35. Sivathamby, K., 1995. Sri Lankan Tamil Society and Politics. Madras: New Century Book House Pvt. Ltd., pp. 1-2.

36. The Hill Country Plantation Worker Communities and the National System-Access and Participation., 1981. Colombo: Marga Institute.

37. Thompson, K., 1996. Key Quotations in Sociology. London: Routledge Publishers., pp. 103-111.

38. Unwin Hyman Dictionary of Sociology, 1999. Glasgow: HarperCollins Publishers.

39. Uyangoda, J., 1995. Life Under Milk Wood. Women Workers in Rubber Plantations: An Overview. Colombo: Women's Education and Research Centre. 